\title{
Electron Bulk Surface Density Variability in Ionosphere during Quiet Days at Low Latitudes
}

\author{
Kadidia Nonlo Drabo ${ }^{1,3}$, Emmanuel Nanéma ${ }^{1,3}$, Jean Louis Zerbo ${ }^{2} \&$ Frédéric Ouattara $^{3}$ \\ ${ }^{1}$ Centre National de la Recherche Scientifique et Technologique (CNRST), Institut de Recherche en Sciences \\ Appliquées et Technologies (IRSAT), 03 BP 7047 Ouagadougou 03, Ouagadougou, Burkina Faso \\ ${ }^{2}$ Université Nazi Boni, UFR/ST, 01 BP 1091 Bobo-Dioulasso 01, Burkina Faso \\ ${ }^{3}$ Université Norbert ZONGO, Laboratoire de Recherche en Météorologie de l'Espace (LAREME), Koudougou, \\ Burkina Faso \\ Correspondence: Emmanuel Nanéma, Université Norbert ZONGO, Laboratoire de Recherche en Météorologie de \\ l’Espace (LAREME), Koudougou, Burkina Faso.E-mail: nanema_emmanuel@yahoo.fr
}

Received: September 5, 2019

Accepted: September 25, 2019 Online Published: September 30, 2019

doi:10.5539/apr.v11n5p21

URL: http://dx.doi.org/10.5539/apr.v11n5p21

\begin{abstract}
This work deals with electron surface density time variation in ionosphere region. The study uses international reference ionosphere (IRI) model for investigation. Total Electron Content (TEC) parameter is carried out at different levels in the F2-layer of ionosphere. The study takes place at Ouagadougou station $\left(12,4^{\circ} \mathrm{N}\right.$ and $358,5^{\circ} \mathrm{E}$ ), in West Africa. Quiet time periods of solar cycle 22 are considered. This study considers only the maximum and minimum phases of solar cycle 22. The five quietest days of the characteristic months in each season are used in the study. Seasonal time profiles of ionosphere parameters highlight relation between Total Electron Content (TEC) and Height of F2-layer ( $\mathrm{hmF} 2)$ in ionosphere region. The results found in this study correlate closely with parameters behavior previously found in other works.
\end{abstract}

Keywords: Ionosphere, Total Electron Content, Height of F2-Layer, Quiet Days, Minimum Phase, Maximum Phase, Characteristic Month

\section{Introduction}

The Sun emits radiations through all the space. These radiations hit the particles in the atmosphere and cause their ionization. From $50 \mathrm{~km}$ up to almost $800 \mathrm{~km}$ in the atmosphere, the density of particles is important (Bauer et al., 1962, 1964; Van Zandt et al., 1960, 1964). This part of the atmosphere is the ionosphere layer. It's the site where reflect radio waves for telecommunication. In this region, the major constituents in particles are $\mathrm{N}_{2}, \mathrm{O}_{2}$ and O (Rishbett et al., 1969). Ionosphere is electrically neutral and moves like a plasma. Different approaches (theoretical and data processing) are used for its modeling (Richmond et al., 1992; Pedatella et al., 2011; Ouattara et al., 2011). The present study uses international reference ionosphere (IRI) model for ionosphere investigation. IRI is a semi-empirical model using data recorded on different stations. The model is usually updated and is on-line accessible. This study uses the 2012-version of the model to carry out TEC and hmF2 parameters during minimum (1985) and maximum (1990) of solar cycle 22. The parameters are obtained for the different seasons of 1985 and 1990 at Ouagadougou station located in West Africa, near the equator.

\section{Methodology-Fundamentals}

This study is based on the following three core principles (Nanéma et al., 2018a, 2018b): (i) The characteristic months of spring, summer, autumn and winter are respectively March, June, September and December ; (ii) The five quietest days of each characteristic month ( $\mathrm{Aa} \leq 20 \mathrm{nT}$ ) are considered; (iii) Solar minimum is characterized by sunspot number $\mathrm{Rz}<20$ while the maximum is characterized by $\mathrm{Rz} \geq 100.1985$ and 1990 are respectively the minimum and the maximum of solar cycle 22 .

Using (ii) principle enables to write TEC time value as follows:

$$
\operatorname{TEC}_{\mathbf{i}}=\frac{\sum_{\mathrm{j}=1}^{5} \mathrm{TEC}_{\mathrm{i}, \mathrm{j}}}{5}
$$


where $\mathrm{TEC}_{\mathrm{i}}$ is the hourly mean value of Total electron content for a selected month at "i" hour; $\mathrm{TEC}_{\mathrm{i}, \mathrm{j}}$ pointing out the hourly average value of Total electron content at " $\mathrm{i}$ " hour, and " $\mathrm{j}$ " quiet day.

The same approach enables to write $\mathrm{hmF} 2$ time value as follows:

$$
h m F 2_{i}=\frac{\sum_{j=1}^{5} h_{F F} 2_{i, j}}{5}
$$

where $\mathrm{hmF} 2_{\mathrm{i}}$ is the hourly mean value of Height of $\mathrm{F} 2$-layer for a selected month at " $\mathrm{i}$ " hour; $\mathrm{hmF} 2_{\mathrm{i}, \mathrm{j}}$ pointing out the hourly average value of Height of F2-layer at "i" hour, and "j" quiet day.

Then, time parameter is used to link TEC and hmF2 values. This shows electron surface density (TEC) time variation at different levels $(\mathrm{hmF} 2)$ in ionosphere F2-layer.

Table 1 presents the retained days obtained by selecting the quietest in each characteristic month of the four seasons.

Table 1. Quietest days of characteristic months on minimum and maximum of solar cycle 22

\begin{tabular}{ccccccc}
\hline & & & \multicolumn{3}{c}{ Months } \\
Cycle & Phase & Year & March & June & September & December \\
\hline \multirow{2}{*}{22} & Min & 1985 & $9,13,21,22,25$ & $3,14,16,18,19$ & $2,3,4,5,29$ & $8,9,21,23,29$ \\
& & & & & & $10,11,19,21,29$ \\
& Max & 1990 & $4,10,16,17,31$ & $16,17,20,21,30$ & $2,3,27,29,30$ & 10,19 \\
\hline
\end{tabular}

Local Time (LT) is linked to Universal Time by the following relation (equation (3)):

$$
\mathbf{L T}=\mathbf{U T}+\frac{\text { longitude }}{15}
$$

The longitude of Ouagadougou is $358.5^{\circ} \mathrm{E}$.

Using the following approximation:

$$
358.5^{\circ} \sim 0^{\circ}
$$

Equation (3) becomes (5):

$$
\mathbf{L T}=\mathbf{U T}
$$

The approximation (equation (4)) is possible because of the proximity of Ouagadougou station to the Zero Meridian. The model is run in these conditions.

\section{Result and Discussion}

TEC and hmF2 time values calculated by use of equations (1) and (2) enable to get the following plots (figures 1 and 2), that are the parameters time profiles during minimum and maximum of solar cycle 22 at Ouagadougou station.

The different panels are the seasonal time profiles (spring, summer, autumn and winter) of TEC and hmF2 during quiet days on minimum and maximum of solar cycle 22 . 


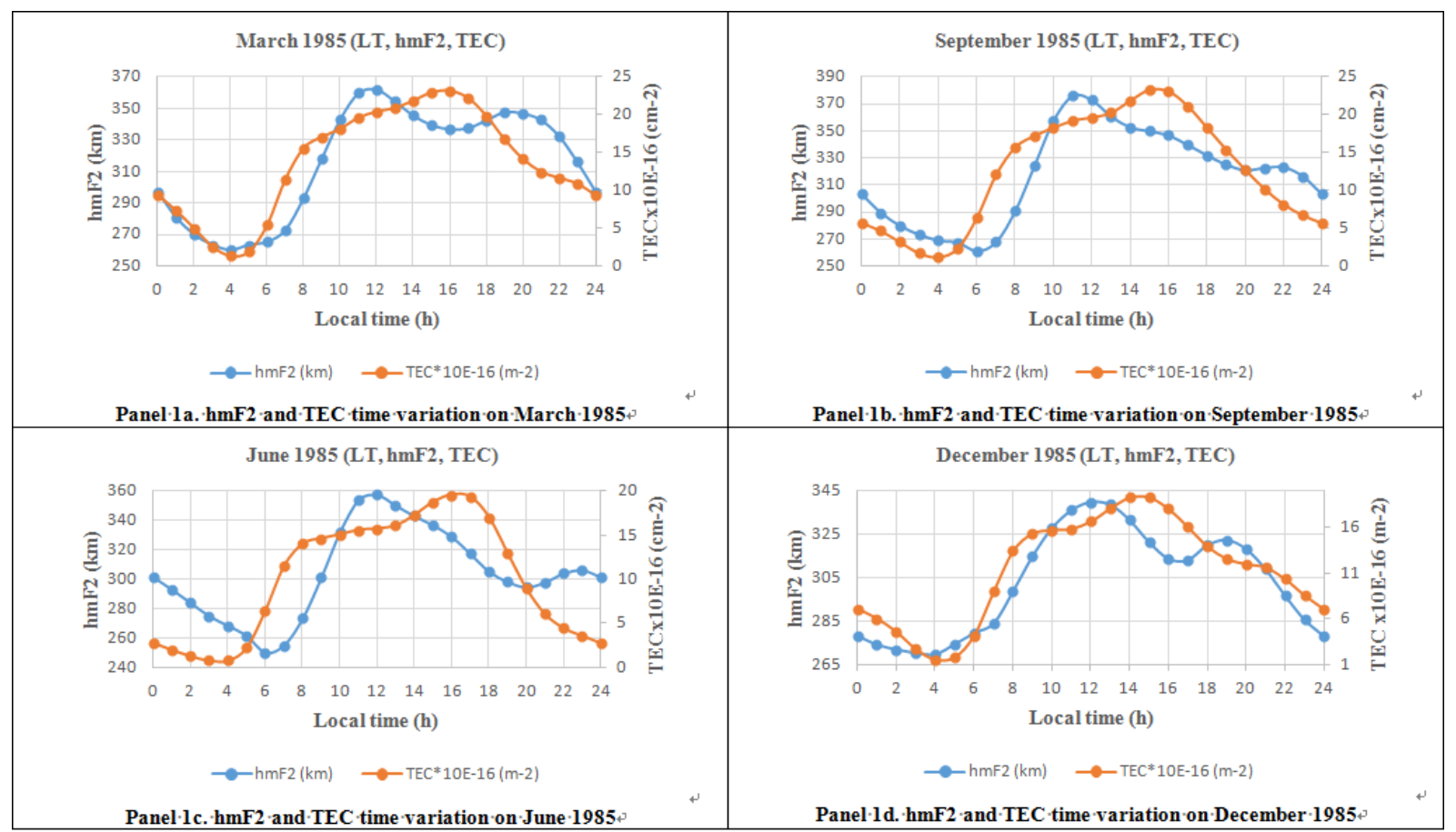

Figure 1. hmF2 and TEC time profiles at minimum of solar cycle 22 at Ouagadougou station

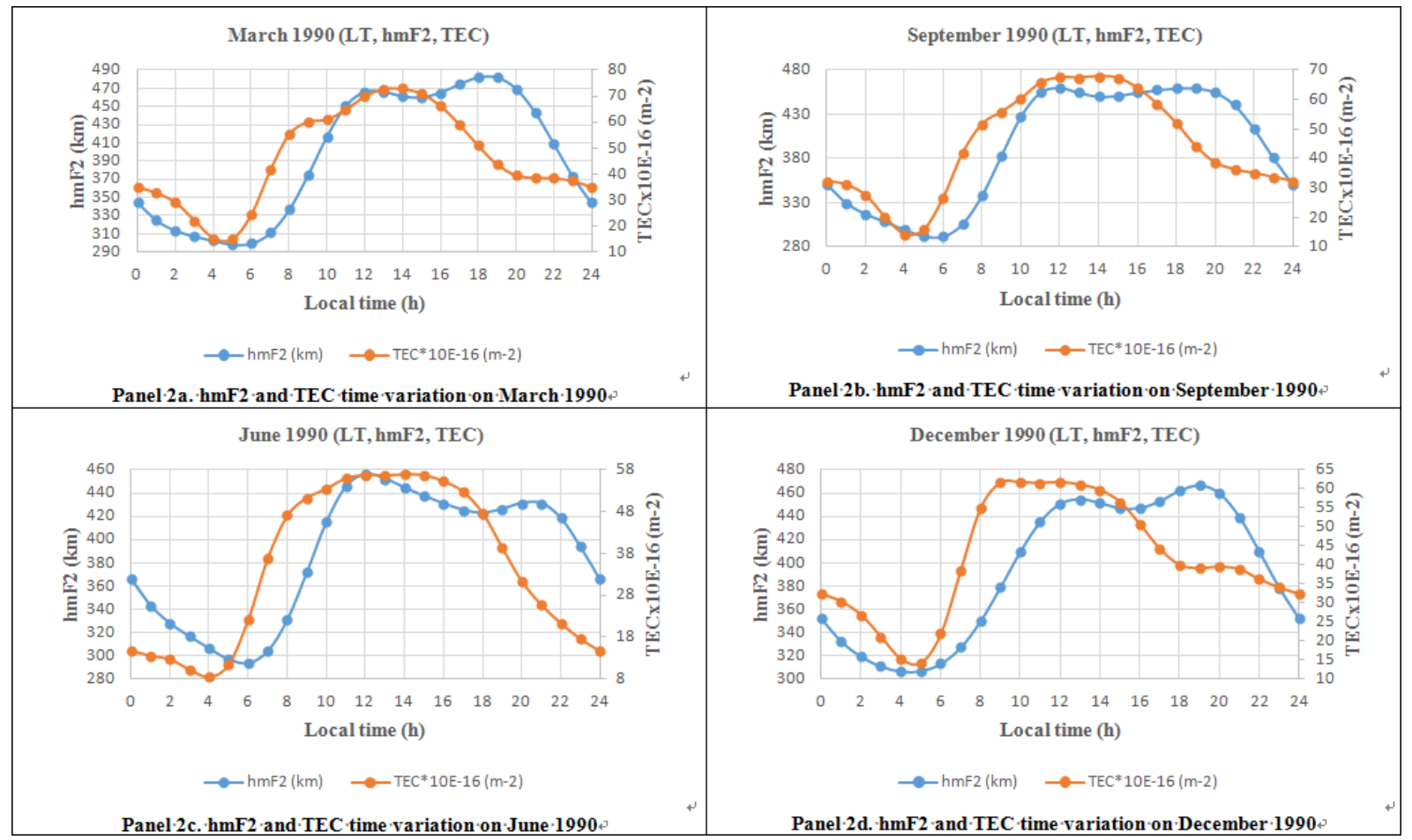

Figure 2. hmF2 and TEC time profiles at maximum of solar cycle 22 at Ouagadougou station

Figure 1 presents $\mathrm{hmF} 2$ and TEC time profiles. $\mathrm{X}$-axis represents the time, while hmF2 and TEC are respectively on the primary Y-axis and the secondary Y-axis. Panels $1 \mathrm{a}, 1 \mathrm{~b}, 1 \mathrm{c}$, and $1 \mathrm{~d}$ present $\mathrm{hmF} 2$ and TEC profiles on spring, autumn, summer and winter at the minimum of solar cycle 22. The panels show that at minimum solar cycle phase, TEC time profile decreases at nighttime (from 0.00 LT up to $04.00 \mathrm{LT}$ and from 16.00 LT up to 24.00 LT) and increases during daytime. This means that during nighttime, electron bulk surface density values are low, compared to those at daytime. The difference of ionization of F2-layer between daytime and nighttime 
causes this phenomenon. During daytime, ionization is higher than that at nighttime. F2-layer raises to high values from nighttime to daytime with its maximum at $12.00 \mathrm{LT}$. So, during nighttime, F2-layer is low compared to its position at daytime.

Figure 2 presents $\mathrm{hmF} 2$ and TEC time profiles on Panels $2 \mathrm{a}, 2 \mathrm{~b}, 2 \mathrm{c}$, and $2 \mathrm{~d}$. X-axis represents time variation along the characteristic month of spring, autumn, summer and winter at the maximum of solar cycle 22 . Figure 2 shows that at maximum solar cycle phase, TEC profile decreases at nighttime and increases at daytime. This has been previously found on solar minimum. During this phase, F2-layer also presents the same behavior, compared to the minimum of solar cycle phase.

Figures 1 and 2 show that at maximum, hmF2 and TEC values are superior to those at minimum. This means that F2-layer raises to high values from minimum to maximum in the same solar cycle phase. At the same time, electron bulk surface density also raises to high values. This correlates with the result of critical frequency in a recent study (Nanéma et al., 2018c, 2018d) that shows foF2 values are higher on maximum solar than those on minimum solar cycle phase.

Figures 3 and 4 highlight TEC seasonal variation on solar minimum and maximum respectively.

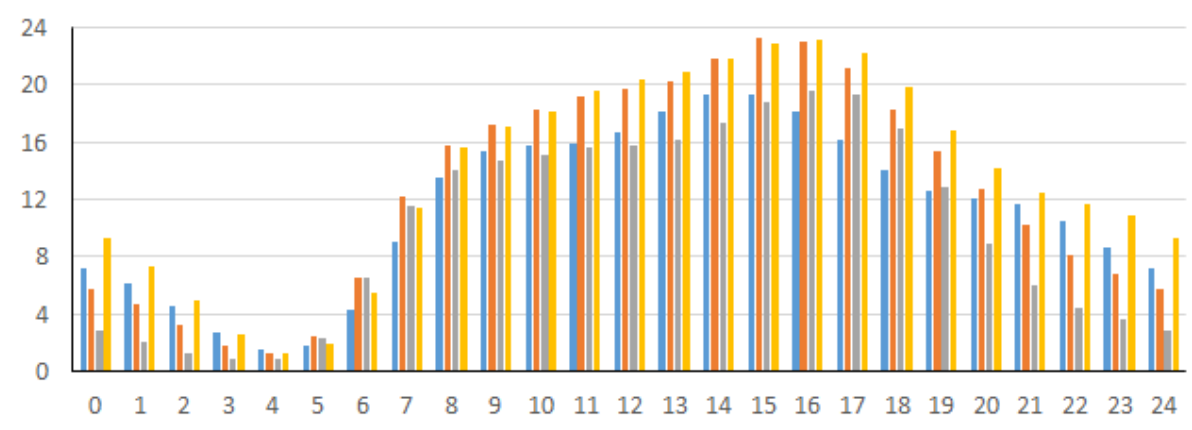

Figure 3. TEC seasonal variation on solar minimum

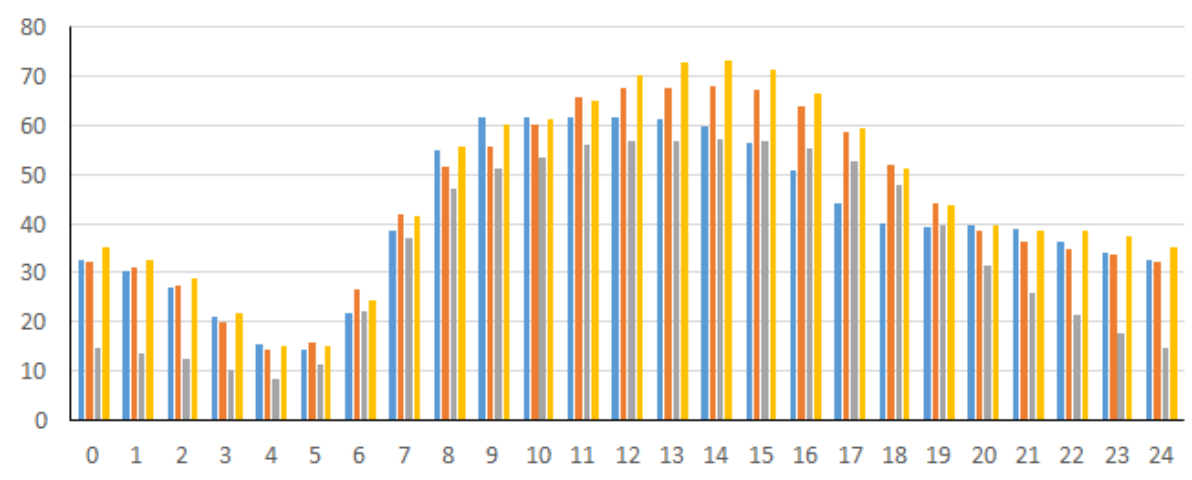

Figure 4. TEC seasonal variation on solar maximum

Figure 3 shows that on solar minimum, electron bulk surface density values are high on spring and autumn and low on summer and winter during daytime (from 08.00 LT to $17.00 \mathrm{LT}$ ) and around. At nighttime (from $0.00 \mathrm{LT}$ to $04.00 \mathrm{LT}$ and from $20.00 \mathrm{LT}$ to $24.00 \mathrm{LT}$ ), electron surface density is higher on winter than that on summer. This last result highlights winter anomaly phenomenon (Ouattara et al., 2012; Nour et al., 2015).

On solar maximum (figure 4), electron bulk surface density is higher on winter than that on summer all day long, except at the beginning of nighttime, during the descending phase (from 15.00 LT to $19.00 \mathrm{LT}$ ). This result well reproduces winter anomaly, previously found on solar minimum. TEC values are higher on spring and autumn than that on summer. At low latitudes, ionosphere F2-layer ionization is higher on spring and autumn than on summer during solar maximum.

\section{Conclusion}

In this study, electron bulk surface density behavior is highlighted at different positions of F2-layer on a station located at low latitudes. This study shows that electron bulk surface density parameter raises with F2-layer value. Ionization causes the difference of TEC values from nighttime to daytime, from minimum to maximum of solar 
cycle phase and between the different seasons of the year. This study shows the effects of the three variables (solar cycle phase, time and season) on TEC and hmF2. TEC study reproduces winter anomaly phenomenon. This result has already been found on NmF2 study. Solar ionization enhances electron surface density in ionosphere F2-layer. This is shown between the minimum and the maximum of solar cycle phase, and from nighttime to daytime. Winter anomaly shows that solar is not the only factor of ionization in ionosphere. We will focus a next study on the other factors of ionization in the atmosphere.

\section{Conflict of interests}

The authors declare that there is no conflict of interests regarding the publication of this paper.

\section{References}

Bauer, S. J., \& Jackson, J. E. (1962). Rocket measurements of the electron density distribution in the topside ionosphere. Journal of Geophysical Research, 67, 1675-1677.

Bauer, S. J., Blumble, L. J., Donley, J. L., Fitzenreiter, R. J., \& Jackson, J. E. (1964). Simultaneous rocket and satellite measurements of the topside ionosphere. Journal of Geophysical Research, 69, 186-189.

Nanéma, E., Gnabahou, D. A., Zoundi, C., \& Ouattara, F. (2018). Modeling the Ionosphere during Quiet Time Variation at Ouagadougou in West Africa. International Journal of Astronomy and Astrophysics, 8, 163-170.

Nanéma, E., Konaté, M., Gnabahou, A. D., \& Ouattara, F. (2018). Effects of Height of F2-Layer on Critical Frequency by Use of Data at Ouagadougou Station. Applied Physics Research, 10(5), 57-60.

Nanéma, E., Ouédraogo, I., Zoundi, C., \& Ouattara, F. (2018). Electron bulk Surface Density Effect on Critical Frequency in the F2-Layer. International Journal of Geosciences, 9, 572-578.

Nanéma, E., Zerbo, J. L., Konaté, M., \& Ouattara, F. (2018). Height of F2-layer peak parameter effects on critical frequency by IRI. Journal of Scientific and Engineering Research, 5(12), 62-68.

Nour, A. M., Frédéric, O., Louis, Z. J., Frédéric, G. A. M., Emmanuel, N., \& François, Z. (2015). Statistical Study of foF2 Diurnal Variation at Dakar Station from 1971 to 1996: Effect of Geomagnetic Classes of Activity on Seasonal Variation at Solar Minimum and Maximum. International Journal of Geosciences, 6, 201-208.

Ouattara, F., \& Rolland, F. (2011). Variability of CODG TEC and IRI 2001 Total Electron Content (TEC) during IHY Campaign Period (21 March to 16 April 2008) at Niamey under Different Geomagnetic Activity Conditions. Scientific Research and Essays, 6, 3609-3622.

Ouattara, F., Gnabahou, A., \& Amory Mazaudier, C. (2012). Seasonal, Diurnal and Solar-Cycle Variations of Electron Density at Two West Africa Equatorial Ionization Anomaly Stations. International Journal of Geophysics, 2012. Article ID: 640463.

Pedatella, N. M., Forbes, J. M., Maute, A., Richmond, A. D., Fang, T.-W., Larson, K. M., \& Millward, G. (2011). Longitudinal variations in the $\mathrm{F}$ region ionosphere and the topside ionosphere-plasmasphere: Observations and model simulations. Journal of Geophysical Research, 116, A12309.

Richmond, A. D., Ridley, E. C., \& Roble, R. G. (1992). A thermosphere/ionosphere general circulation model with coupled electrodynamics. Geophysics Research Letter, 19, 601.

Rishbett, H., \& Gariott, O., K. (1969). Introduction to ionospheric physics. In J. Van Mieghem (Ed.), International Geophysics Series (pp. 160-189). Academic Press, New York.

Van Zandt, T. E., \& Knecht, R. W. (1964). The structure and physics of the upper atmosphere. In D. P. Le Galley \& A. Rosen (Eds.), Space Physics (pp. 166-225). Willey, New York.

Van Zandt, T. E., Norton, R. B., \& Stonehocker, G. H. (1960). Photochemical rates in the equatorial F2 region from the 1958 eclipse. Journal of Geophysical Research, 65, 2003-2009.

\section{Copyrights}

Copyright for this article is retained by the author(s), with first publication rights granted to the journal.

This is an open-access article distributed under the terms and conditions of the Creative Commons Attribution license (http://creativecommons.org/licenses/by/4.0/). 